\title{
๖The Slowdown Tends to Be Greater for Stronger Tropical Cyclones
}

\author{
YUAN SUn, ${ }^{\mathrm{a}}$ ZHONG ZHONG, ${ }^{\mathrm{a}, \mathrm{b}}$ Tim LI, ${ }^{\mathrm{c}, \mathrm{d}, \mathrm{e}}$ LAN Yi, ${ }^{\mathrm{f}}$ AND YiXUAN SHEN ${ }^{\mathrm{a}}$ \\ ${ }^{a}$ College of Meteorology and Oceanography, National University of Defense Technology, Nanjing, China \\ b Jiangsu Collaborative Innovation Center for Climate Change, School of Atmospheric Sciences, Nanjing University, Nanjing, China \\ ${ }^{\mathrm{c}}$ International Pacific Research Center, University of Hawai'i at Mānoa, Honolulu, Hawaii \\ ${ }^{\mathrm{d}}$ Department of Atmospheric Sciences, University of Hawai'i at Mānoa, Honolulu, Hawaii \\ ${ }^{\mathrm{e}}$ Joint International Research Laboratory of Climate and Environmental Change, Nanjing University of Information \\ Science and Technology, Nanjing, China \\ ${ }^{\mathrm{f}}$ Chinese Academy of Meteorological Sciences, Beijing, China
}

(Manuscript received 11 June 2020, in final form 12 April 2021)

\begin{abstract}
Understanding the impact of climate change on tropical cyclones (TCs) has become a hot topic. The slowdown of TC translation speed contributes greatly to the locally accumulated TC damage. While the recent observational evidence shows that TC translation speed has decreased globally by $10 \%$ since the mid-twentieth century, the robustness of the trend is questioned by other studies as effects of changes in observational capability can strongly affect the global trend. Moreover, none of the published studies considered the dependence of TC slowdown on TC intensity. This is the caveat of these analyses as the effect of TC slowdown is closely related to TC intensity. Here, we investigate the relationship between TC translation speed trend and TC intensity, and reveal possible reasons for the trend. We show that the global slowing trend without weak TC moments $\left(\leq 17 \mathrm{~m} \mathrm{~s}^{-1}\right)$ is about double of that with weak TC moments in a recent study. This is because the slowing trend is dominated by the trend of the strong TCs. Stronger (weaker) TCs tend to be controlled more by upper-level (lower-level) steering flow, and the calculated trend of upper-level steering flow is much larger than that of lower-level steering flow. This may be an important reason for the large difference between the slowing trend without weak TC moments and that with weak TC moments. Furthermore, the changes of TC tracks (including interbasin trend and latitudinal shift), which are partly attributed to data inhomogeneity, make a much larger contribution to the slowing trend, compared with the weakening of tropical circulation, which is related to anthropogenic warming.
\end{abstract}

KEYWORDS: Tropical cyclones; Climate change; Anthropogenic effects/forcing

\section{Introduction}

Understanding the response of tropical cyclones (TCs) to a changing climate related to anthropogenic warming is a topic of great scientific interest and public concern (Emanuel 2005; Knutson et al. 2010; Kossin 2018; Moon et al. 2019). A recent study by Kossin (2018) showed that the observed TC translation speed $\left(U_{\mathrm{TS}}\right)$ has slowed down globally by about $10 \%$ since the mid-twentieth century, which was assumed to be driven primarily by anthropogenic forcing. A study using high-resolution regional climate models also found that several observed TCs would have been slower had they occurred in a warmer climate (Gutmann et al. 2018). Greenhouse gas-induced global warming, both in the past and projected, is expected to slow down the general atmospheric circulation, especially the summertime tropical circulation (Held and Soden 2006; Vecchi et al. 2006; Vecchi and Soden 2007; Bellomo and Clement 2015; He and Soden 2015; He et al. 2017). There is a priori expectation that the reduction in the strength of tropical circulation can slow down $U_{\text {TS }}$, as TCs are guided by large-scale ambient environmental flow (George and Gray 1976).

¿ Denotes content that is immediately available upon publication as open access.

Corresponding author: Zhong Zhong, zhong_zhong@yeah.net
The robustness of the observed $U_{\mathrm{TS}}$ trend analysis, however, has been questioned recently due to data inhomogeneity in the past decades (Chan 2019; Lanzante 2019; Moon et al. 2019). In the presatellite era before 1965, systematic biases were expected to exist in the data used for detecting TCs, which could lead to spurious trend in $U_{\text {TS }}$. Thereby, the global slowdown of $U_{\mathrm{TS}}$ in the past decades revealed by Kossin (2018) may not be a real climate signal, or may be overestimated as suggested by Moon et al. (2019). Moreover, even though both $U_{\mathrm{TS}}$ and tropical circulation strength decreased in the past decades, it is still unclear whether the global slowdown of $U_{\mathrm{TS}}$ is mainly due to the weakening of tropical circulation (Guglielmi 2018). Besides the weakening of tropical circulation, the changes of TC tracks, including interbasin frequency trend and systematic meridional shift (latitudinal shift), could also introduce changes in $U_{\text {TS }}$ because TC steering flow, which is the surrounding environmental wind, varies with basin and latitude (i.e., different basins have different mean-state steering flows, and $U_{\mathrm{TS}}$ generally increases with the latitude of TC center) (Lanzante 2019; Moon et al. 2019; Wang et al. 2020). Besides the unclear contributions to the global slowdown of $U_{\mathrm{TS}}$ by tropical circulation weakening, interbasin trend, and latitudinal shift, it also remains unclear whether the interbasin trend and latitudinal shift are entirely due to data artifacts related to changes in observational capability, or whether a climate signal may have played a role. These questions need careful scrutiny before we can have high confidence that the trend shown in Kossin (2018) reflects a true global slowdown of $U_{\mathrm{TS}}$. 

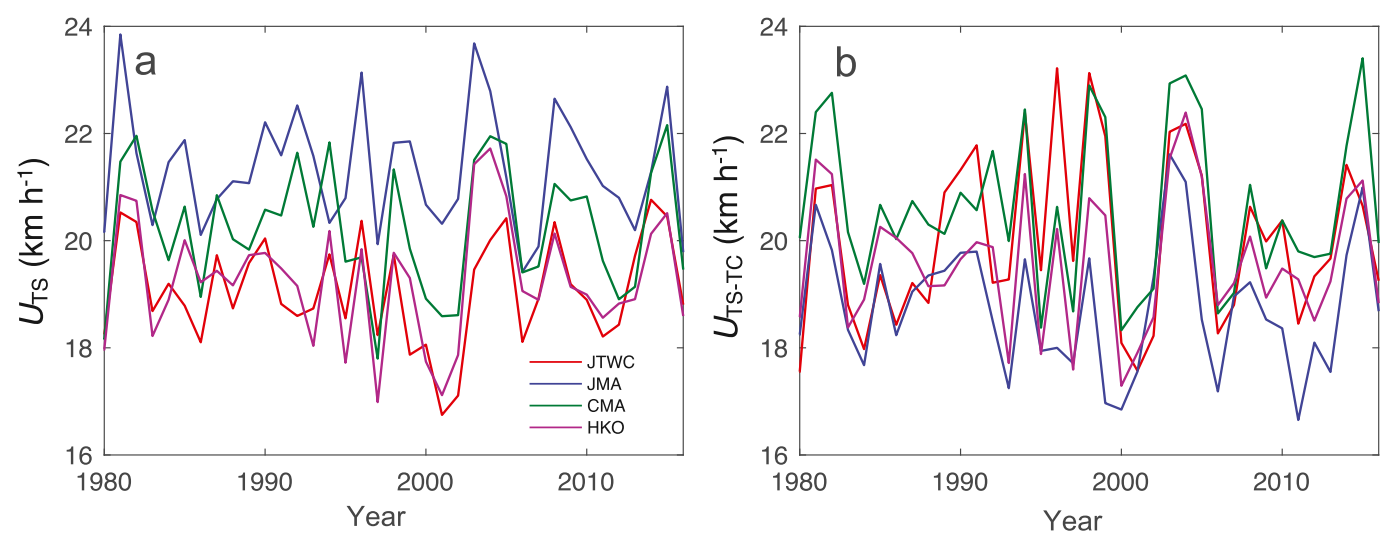

FIG. 1. Comparison between two measures. Time series of annual-mean $U_{\mathrm{TS}}$ with all the records and $U_{\mathrm{TS}-\mathrm{TC}}$ with only the records reaching the intensity threshold of $17 \mathrm{~m} \mathrm{~s}^{-1}$ over the western North Pacific calculated from four best track datasets.

Despite the dominant role of TCs over water in contributing to the slowing trend of $U_{\mathrm{TS}}$ over the globe, the changes in $U_{\mathrm{TS}}$ over land are of more public concerns than those over the ocean (Kossin 2018; Patricola 2018). Regardless of TC intensity, the slowdown of $U_{\mathrm{TS}}$ is very likely to compound flooding by increasing total local rainfall from TCs, which is inversely proportional to $U_{\mathrm{TS}}$ (Guglielmi 2018; Kossin 2018; Patricola 2018). The unprecedented rainfall totals associated with the "stall" of Typhoon Morakot over Taiwan in 2009 (Chien and Kuo 2011) and of Hurricane Harvey over Texas in 2017 (Emanuel 2017; Risser and Wehner 2017; Van Oldenborgh et al. 2017) provide notable examples of the relationship between $U_{\mathrm{TS}}$ and regional rainfall amount. Nevertheless, the effects of TC slowdown over water cannot be ignored as the data related to the TCs over water amount to more than $90 \%$ of the global best track data. TC-generated waves have long been a major concern for vessels and installations at sea (Sampson et al. 2010). Wave growth time, and ultimately the amount of local wave enhancement, is critically linked to and extremely sensitive to $U_{\mathrm{TS}}$ (Bowyer and MacAfee 2005; Lazarus et al. 2013).

Both TC-related rain rate and wave height have been shown to be functions of TC intensity, with greater rain rate and wave height linked to stronger TCs (Lonfat et al. 2004; Bowyer and MacAfee 2005). To assess the impacts of TC slowdown on local TC rainfall and waves, it is necessary to address this question: Is it the translation speed of weak TCs or strong TCs that has slowed down with warming in the past decades? On the other hand, as the lack of satellite data in the presatellite era could increase the uncertainty of the observed $U_{\mathrm{TS}}$ trend (Moon et al. 2019), it is necessary to find a more reliable measure, which is relatively less sensitive to the data inhomogeneity related to changes in observational capability, to reestimate the trend of $U_{\mathrm{TS}}$ in the past decades.

\section{Methodology and data}

\section{a. Summary of methods}

To be consistent with Kossin (2018) for comparison purposes, the period 1949-2016 was chosen, and the data from the Joint Typhoon Warning Center (JTWC) and U.S. National
Hurricane Center (NHC) were combined for global coverage. More details on these datasets can be found in the Methods section of Kossin (2018). Consistent with the methods in Kossin (2018), $U_{\text {TS }}$ is calculated using neighboring locations along each TC track; the data at a 6-h interval are recorded throughout the lifetime of each TC. Distances between locations are calculated along a great arc of a circle. The Durbin-Watson test is used to assess autocorrelation among the residuals of time series data.

According the to World Meteorological Organization (WMO) definition of TCs, "weak TCs" with intensity $\leq 17 \mathrm{~m} \mathrm{~s}^{-1}$ are technically not TCs but tropical depressions (TDs). Kossin (2018) included TDs when calculating the annual-mean $U_{\mathrm{TS}}$. In this study, we calculate the annual-mean $U_{\mathrm{TS}}$ excluding TDs, namely, the annual mean with only the TC records reaching an intensity threshold of $17 \mathrm{~m} \mathrm{~s}^{-1}$ (i.e., $U_{\text {TS-TC }}$ ).

Due to large uncertainties in TC intensity observations, there are some differences (in terms of standard deviation) in calculated annual-mean $U_{\mathrm{TS}}$ and $U_{\mathrm{TS}-\mathrm{TC}}$ between different datasets (Fig. 1). Note that the standard deviation of $U_{\mathrm{TS}} / U_{\mathrm{TS}-\mathrm{TC}}$ in a specific year can be calculated by

$$
\begin{aligned}
\sigma_{j} & =\sqrt{\frac{1}{4} \sum_{i=1}^{4}\left(U_{i}-\bar{U}\right)^{2}}, \\
\bar{U} & =\frac{1}{4} \sum_{i=1}^{4} U_{i},
\end{aligned}
$$

where $i$ represents the order of these different best track datasets (JTWC, JMA, CMA, and HKO, defined in section 2b), $U_{i}$ is the annual-mean $U_{\mathrm{TS}} / U_{\mathrm{TS}-\mathrm{TC}}$ from the $i$ th best track dataset, $\bar{U}$ is the averaged $U_{\mathrm{TS}} / U_{\mathrm{TS}-\mathrm{TC}}$ of the four best track datasets, and $\sigma_{j}$ is the standard deviation of $U_{\mathrm{TS}} / U_{\mathrm{TS}-\mathrm{TC}}$ in a specific year (the $j$ th year).

\section{b. Data availability}

The TC data analyzed in this study were taken from the International Best Track Archive for Climate Stewardship (IBTrACS) v03r10 (Knapp et al. 2010; available at 

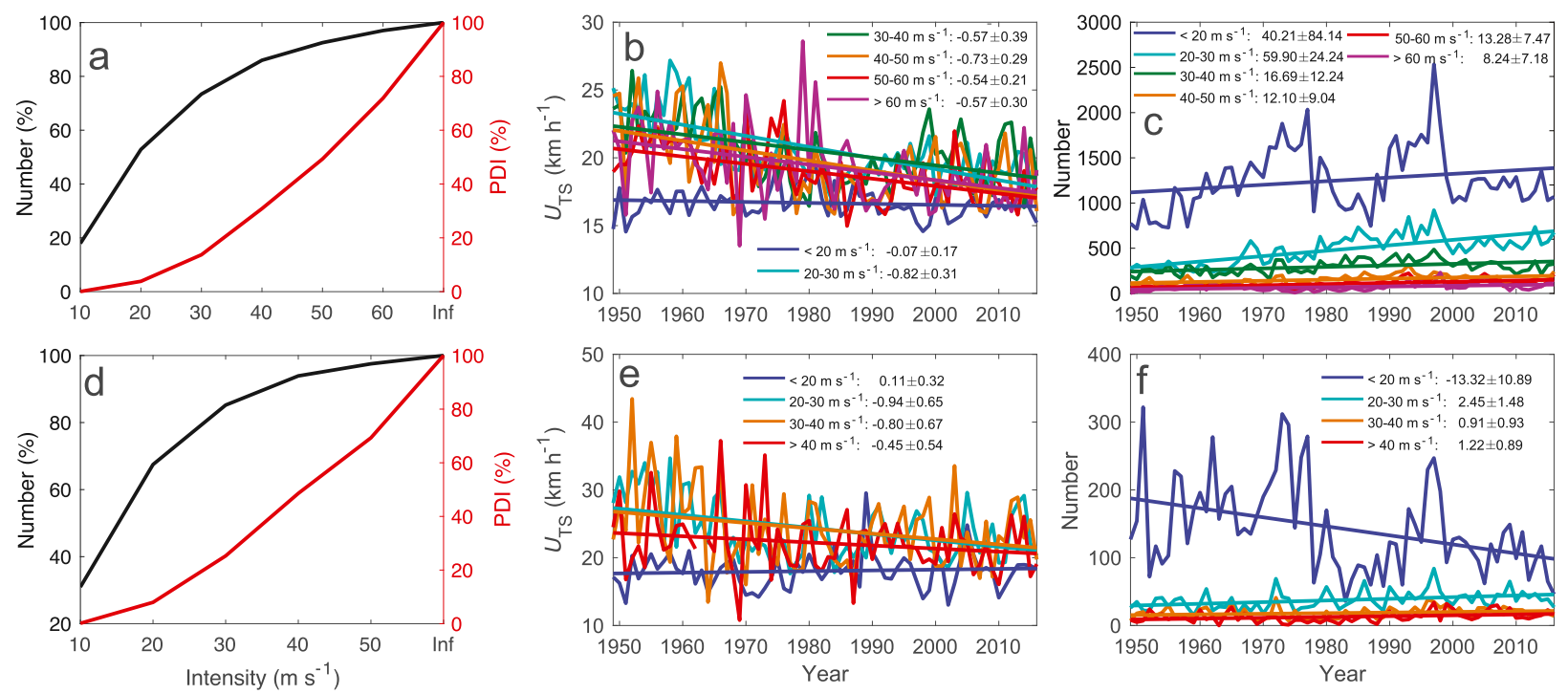

FIG. 2. Relationship between TC translation speed trend and TC intensity. Cumulative frequency function of TC intensity in $10 \mathrm{~m} \mathrm{~s}{ }^{-1}$ bins with respect to TC and PDI, and time series of annual-mean translation speed ( $\left.U_{\mathrm{TS}}\right)$, number, and their linear trends in various intensities with $10 \mathrm{~m} \mathrm{~s}^{-1}$ bins during 1949-2016 for (a)-(c) the global TCs and (d)-(f) the TCs over land. Linear trends (solid lines) are shown, which are also quantitatively presented with their $95 \%$ two-sided confidence bounds (annotated values; $\mathrm{km} \mathrm{h}^{-1} \mathrm{decade}{ }^{-1}$ ). Note that the TC moments without intensity records are assumed to be the TC moments with intensity $<10 \mathrm{~m} \mathrm{~s}^{-1}$, and "Number" ("PDI") in the two left panels is not simple TC number (PDI) but the contribution from the TC records below certain intensity to the total number (PDI) of the region.

http://www.ncdc.noaa.gov/ibtracs/, file Allstorms.ibtracs_all. v03r10.nc). The overland TC positions were determined by the 2-Minute Gridded Global Relief Data (ETOPO2v2; https:// www.ngdc.noaa.gov/mgg/global/etopo2.html). Large-scale environmental steering flow and tropical circulation were all calculated from the National Centers for Environmental Prediction-National Center for Atmospheric Research Global Reanalysis (NCEP-NCAR; Kalnay et al. 1996; https://www.esrl. noaa.gov/psd/data/gridded/data.ncep.reanalysis.html).

For the TCs over the western North Pacific, there are four best track datasets from four different agencies: the Joint Typhoon Warning Center (JTWC), the Japan Meteorological Agency (JMA), the China Meteorological Administration (CMA), and the Hong Kong Observatory (HKO). We used them to calculate the differences in $U_{\mathrm{TS}}$ and $U_{\mathrm{TS}-\mathrm{TC}}$ among the four datasets. Note that the four best track datasets are all included in IBTrACS v03r10.

\section{Results}

\section{a. Relationship between TC translation speed trend and TC intensity}

As the TC rain rate and wave height are largely determined by TC intensity (Lonfat et al. 2004), there is a possibility for offsetting the effect of TC slowdown if the trend in $U_{\mathrm{TS}}$ is dominated by weaker TCs and for compounding the effect if the trend is dominated by stronger TCs (Kossin 2018). Besides the rainfall and waves associated with TCs, TC wind is also a well-known destructive factor, which is often used to estimate the destructive potential of TCs (Emanuel 2005; Knutson et al. 2010; Lin et al. 2015; Sun et al. 2017). The power dissipation index (PDI) proposed by Emanuel (2005) is widely used to estimate the destructive potential of a TC, which is defined as the sum of the cube of the maximum wind speed over TC lifetime. For a given TC or a given region, the total TC rainfall, wave height, and PDI are all functions of TC intensity and duration, with greater rainfall and wave height linked to larger PDI. Moreover, since the rainfall and wave information of each TC is difficult to obtain while the PDI of each TC can be easily obtained from a best track dataset, the PDI can be used to roughly estimate $\mathrm{TC}$-induced rainfall and wave power, regardless of TC size.

Our calculations reveal that despite the relatively large proportion $(52.8 \%)$ of TC moments with weak intensity $\left(\leq 20 \mathrm{~m} \mathrm{~s}^{-1}\right)$, they only occupy $3.8 \%$ of the total PDI of all TC moments (Fig. 2a). More importantly, the decreasing $U_{\text {TS }}$ trends of relatively strong TC moments with a wide range of intensity $>20 \mathrm{~m} \mathrm{~s}^{-1}$ are all significant at or above the two-sided 95\% confidence level by the Durbin-Watson test (Fig. 2b). However, the $U_{\text {TS }}$ trend of relatively weak TC moments with the intensity $\leq 20 \mathrm{~m} \mathrm{~s}^{-1}$ is nearly flat. This clearly indicates that the $U_{\mathrm{TS}}$ trend of relatively strong TC moments is larger than that of relatively weak TC moments, and the global slowdown tends to be greater for stronger TCs. Moreover, there is a significant increasing (not significant) trend of TC number with relatively strong (weak) intensity of $>20 \mathrm{~m} \mathrm{~s}^{-1}\left(\leq 20 \mathrm{~m} \mathrm{~s}^{-1}\right)$ (Fig. 2c). Note that in this study, TC number refers to the number of TC moments (i.e., records) in the IBTrACS dataset. Together with the small change in $U_{\mathrm{TS}}$ of relatively weak TC 

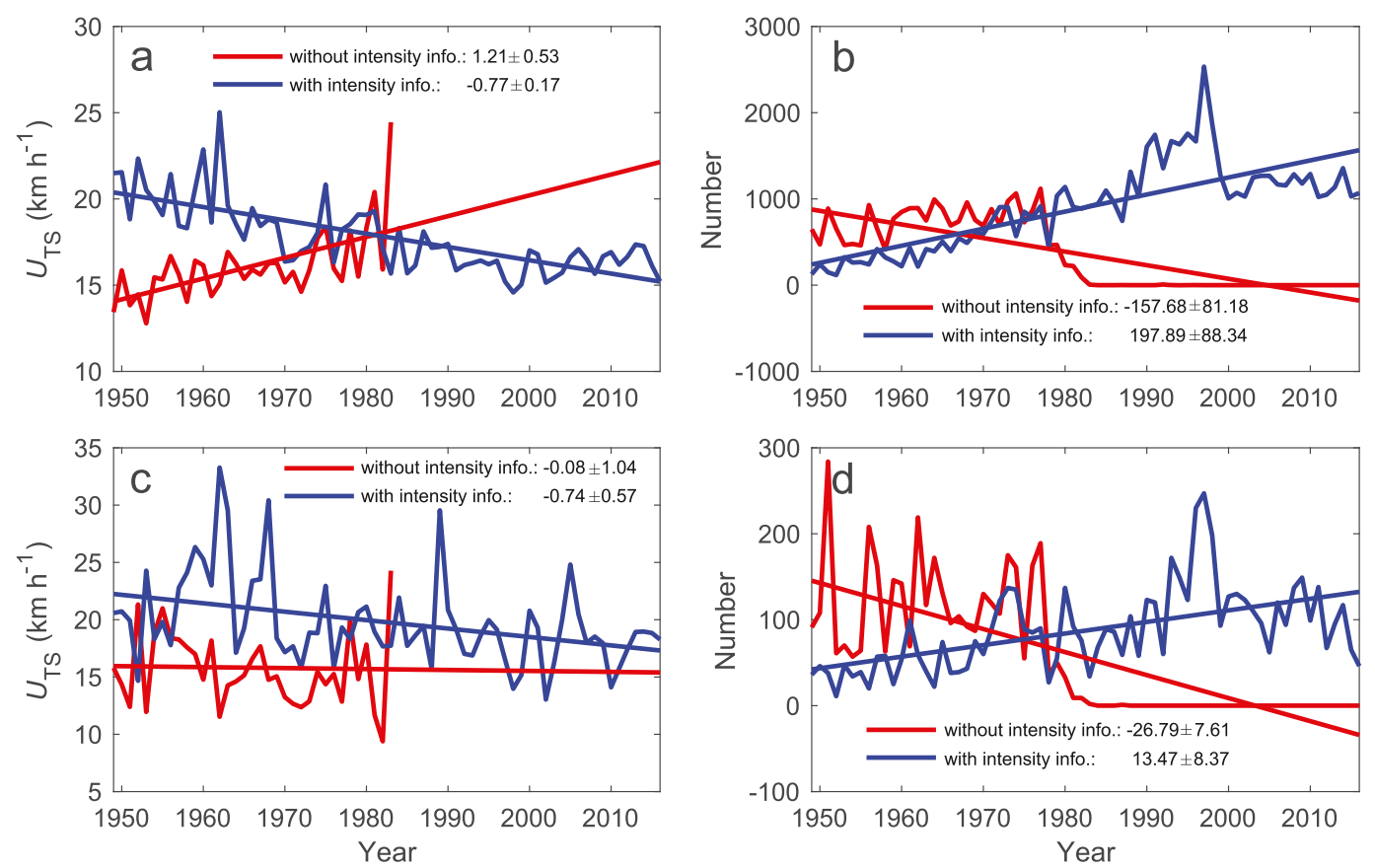

FIG. 3. Effects of weak $\left(<20 \mathrm{~m} \mathrm{~s}^{-1}\right)$ TC moments on TC translation speed. Time series of annual-mean translation speed $\left(U_{\mathrm{TS}}\right)$, number and their linear trends without intensity information (red lines) and with intensity information of $<20 \mathrm{~m} \mathrm{~s}^{-1}$ (blue lines) for (a),(b) the global TCs and (c),(d) the TCs over land. Linear trends (straight lines) are shown, which are also quantitatively presented with their $95 \%$ two-sided confidence bounds (annotated values; $\mathrm{km} \mathrm{h}^{-1}$ decade $^{-1}$ ). Red lines in the two left panels are shorter, due to the lack of records. Note that the TC records with $<20 \mathrm{~m} \mathrm{~s}^{-1}$ intensity in Fig. 2 include both the TC records without intensity information and the TC records with intensity information of $<20 \mathrm{~m} \mathrm{~s}^{-1}$ in Fig. 3.

moments $\left(\leq 20 \mathrm{~m} \mathrm{~s}^{-1}\right)$, this explains the relatively small trend of $U_{\mathrm{TS}}\left[-0.30 \mathrm{~km} \mathrm{~h}^{-1}\right.$ decade $^{-1}$; see Extended Data Table 2 in Kossin (2018)], compared with the $U_{\mathrm{TS}}$ trends of relatively strong TC moments $\left(>20 \mathrm{~m} \mathrm{~s}^{-1}\right)$ in various intensities of $10 \mathrm{~m} \mathrm{~s}^{-1}$ bins (Fig. 2b). Note that the TCs over water account for about $90 \%$ of the TCs in the global best track data. As a result, the findings for the TCs over water are quite similar to those for the global TCs (figure omitted). The results for the TCs over land, which account for about $10 \%$ of the global TCs, are also similar to the results for the global TCs in terms of trends on $U_{\mathrm{TS}}$ and TC number with various intensity (Figs. 2d-f). These results indicate that the trend in $U_{\mathrm{TS}}$ is dominated by relatively strong TCs.

As greater TC rain rate is linked to stronger TCs (Lonfat et al. 2004), the effects of a slowdown of strong TCs over land can compound flooding with increasing local total rainfall from TCs (Kossin 2018; Patricola 2018). Moreover, the effect of TC slowdown over water cannot be ignored, which compounds local wave enhancement by extending the wave growth time (Bowyer and MacAfee 2005; Lazarus et al. 2013). The destructiveness of TC-induced waves tends to be strong due to the TC slowdown over water, especially the slowdown of strong TCs over water, since greater wave enhancement is linked to stronger TCs.

Besides the $U_{\mathrm{TS}}$ trends of strong and weak TCs, the changes of strong and weak TC numbers also contribute to the trend of annual-mean $U_{\mathrm{TS}}$. The relatively weak (strong) TCs with TC intensity $\leq 20 \mathrm{~m} \mathrm{~s}^{-1}\left(>20 \mathrm{~m} \mathrm{~s}^{-1}\right)$ tend to be associated with relatively low (high) $U_{\mathrm{TS}}$ (Figs. 2b,e). Figures 2c and 2f show the significant increasing trend of relatively strong TC number, which can contribute to the increasing trend of annual-mean $U_{\mathrm{TS}}$. However, the increasing trend of $U_{\mathrm{TS}}$ caused by the changes of strong and weak TC numbers cannot offset the decreasing trend of $U_{\mathrm{TS}}$ of strong TCs. As a result, the annualmean $U_{\mathrm{TS}}$ exhibits a significant decreasing trend $[-0.30 \pm$ $0.11 \mathrm{~km} \mathrm{~h}^{-1}$ decade $^{-1}$; see Fig. 1a herein and Extended Data Table 2 in Kossin (2018)]. In addition, Fig. 3 shows the effects of weak TC moments on TC translation speed as "weak TCs" are apt to be undercounted compared with strong TCs in the presatellite era (Moon et al. 2019). As expected, similar to the $U_{\text {TS }}$ of TC moments with weak TC intensity $\left(<20 \mathrm{~m} \mathrm{~s}^{-1}\right)$ in Figs. $2 \mathrm{~b}$ and $2 \mathrm{e}$, the $U_{\mathrm{TS}}$ of the TC moments without intensity information in Figs. 3a and 3c is relatively low compared with that of the TC moments with strong TC intensity $\left(>20 \mathrm{~m} \mathrm{~s}^{-1}\right)$ in Figs. $2 \mathrm{~b}$ and 2e. In fact, the number of TC moments without intensity information is quite large (small) before (after) the introduction of geostationary satellites in 1982 (Figs. 3b,d). Note that as the TC moments without intensity records are assumed to be the TC moments with intensity $<10 \mathrm{~m} \mathrm{~s}^{-1}$ in Fig. 2, the TC records with $<20 \mathrm{~m} \mathrm{~s}^{-1}$ intensity in Fig. 2 include the TC records without intensity information and the TC records with intensity information of $<20 \mathrm{~m} \mathrm{~s}^{-1}$ in Fig. 3. 

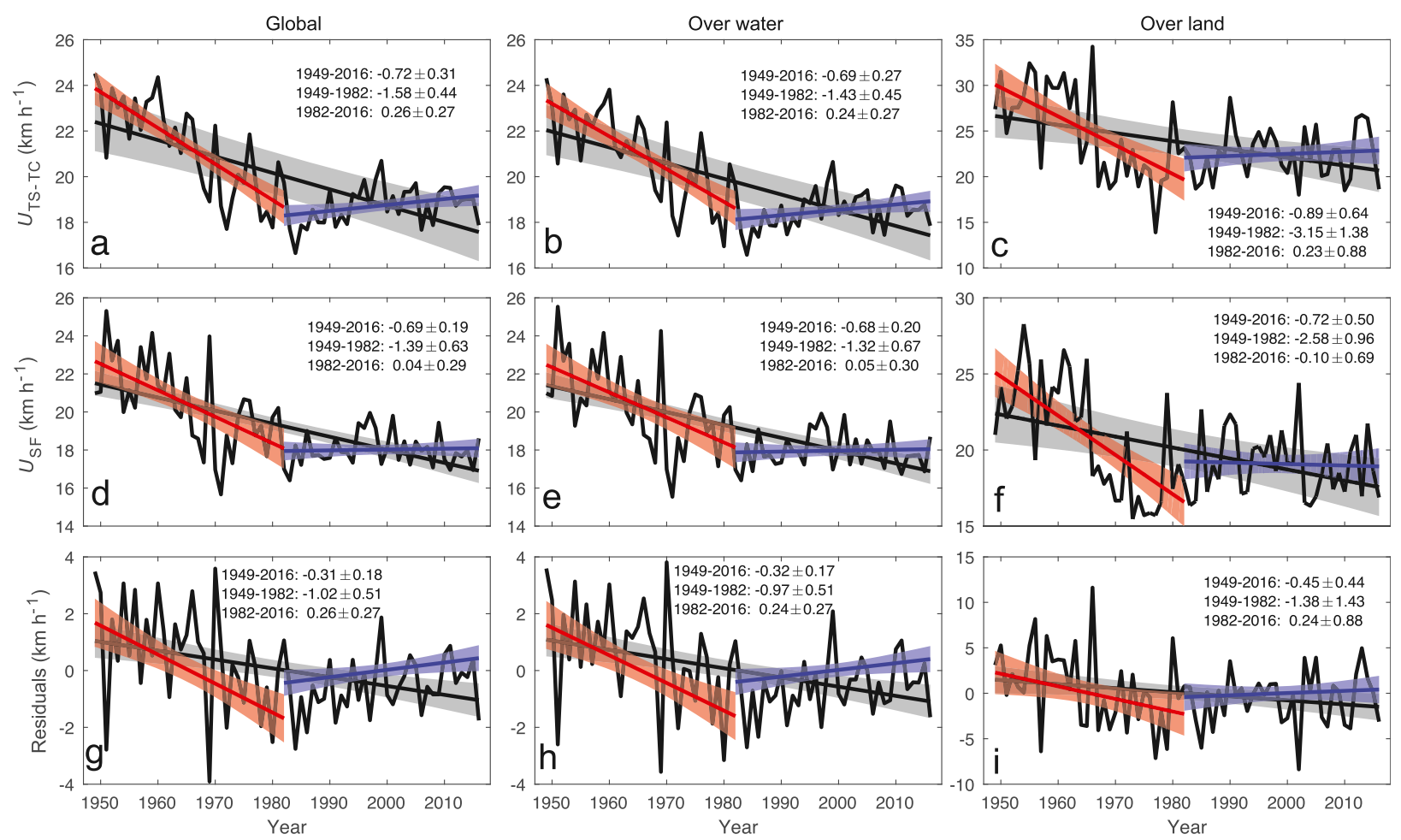

FIG. 4. Contribution of steering flow to TC translation speed. Time series of annual-mean (a)-(c) $U_{\mathrm{TS}-\mathrm{TC}}$ and (d)-(f) $U_{\mathrm{SF}}$ over the globe, water, land, and their linear trends., and (g)-(i) time series of $U_{\mathrm{TS}-\mathrm{TC}}$ with $U_{\mathrm{SF}}$ variability removed, which are calculated from the residuals of single-variate regression of annual-mean $U_{\mathrm{TS}-\mathrm{TC}}$ onto annual-mean $U_{\mathrm{SF}}$ variability. Linear trends (solid lines) are shown with their $95 \%$ two-sided confidence bounds (shading), which are also quantitatively presented (annotated values; $\mathrm{km} \mathrm{h}^{-1} \mathrm{decade}^{-1}$ ). Different colors of lines and shadings represent the trends and bounds during different periods (black: 1949-2016; red: 1949-82; blue: 1982-2016).

\section{b. Annual-mean TC translation speed excluding TDs}

The robustness of the observed trend of $U_{\mathrm{TS}}$ is affected by the uncertainty of the data on TC center location (Guglielmi 2018), although the information on TC center location is relatively reliable than that on TC intensity in various best-track datasets. To test the uncertainty of the observed slowing trend, we take the western North Pacific as an example, and examine the consistency of $U_{\mathrm{TS}}$ among various best-track datasets. Our results show that there are remarkable differences in $U_{\mathrm{TS}}$ among the four datasets (Fig. 1a). This indicates the measure of annual-mean $U_{\mathrm{TS}}$ is not as certain as expected. This is due to the fact that given the differences in criteria used to identify TCs, some weak TCs and weak TC moments with little public concerns may be only identified by some agencies but not by the other agencies (Sun et al. 2018). The detection of the weak TCs with speeds below $35 \mathrm{kt}\left(1 \mathrm{kt} \approx 0.51 \mathrm{~m} \mathrm{~s}^{-1}\right)$, which generally show poorly organized structures, is probably more difficult in the presatellite era before 1965 (Moon et al. 2019).

As mentioned in section 2, we use the measure of the annualmean $U_{\text {TS }}$ excluding TDs (i.e., $U_{\text {TS-TC }}$ ) to reexamine the global trend of TCs over the past decades. Note that weak TCs with intensity $\leq 17 \mathrm{~ms}^{-1}$ (i.e., TDs) are the same as TDs with intensity $\leq 30 \mathrm{kt}$ or $<35 \mathrm{kt}$, as the TC intensity interval is $5 \mathrm{kt}$ in the IBTrACS dataset (e.g., 30 and $35 \mathrm{kt}$, where $30 \mathrm{kt}$ is
$15.43 \mathrm{~m} \mathrm{~s}^{-1}$ and $35 \mathrm{kt}$ is $17.99 \mathrm{~m} \mathrm{~s}^{-1}$ ). We find that $U_{\text {TS-TC }}$ is also a reliable measure, and the time-averaged standard deviation of $U_{\mathrm{TS}-\mathrm{TC}}\left(0.95 \mathrm{~km} \mathrm{~h}^{-1}\right)$ is smaller than that of $U_{\mathrm{TS}}$ $\left(1.14 \mathrm{~km} \mathrm{~h}^{-1}\right)$ among the four best-track datasets from 1980 to 2016 (see Fig. 1).

During the study period (1949-2016), the estimated $U_{\text {TS-TC }}$ trend $\left(-0.72 \mathrm{~km} \mathrm{~h}^{-1}\right.$ decade $^{-1}$; Fig. 4a) is significant above the 99.9\% confidence level and larger than twice the $U_{\text {TS }}$ trend $\left[-0.3 \mathrm{~km} \mathrm{~h}^{-1}\right.$ decade $^{-1}$; see Extended Data Table 2 in Kossin (2018)]. This is because the annually averaged $U_{\text {TS-TC }}$ is mainly determined by the $U_{\mathrm{TS}}$ of the strong TCs with significant slowing trends, and not sensitive to the $U_{\mathrm{TS}}$ of weak TCs (i.e., TDs) with their nearly flat trends (Fig. 2b); that is, the small change in $U_{\mathrm{TS}}$ of weak TC moments (Fig. 2b) is responsible for the large difference between $U_{\mathrm{TS}-\mathrm{TC}}$ and $U_{\mathrm{TS}}$ trends. The difference is similar for the comparison between $U_{\mathrm{TS}-\mathrm{TC}}$ and $U_{\mathrm{TS}}$ trends over water [Fig. 4b; also see Extended Data Table 2 in Kossin (2018)], as the TCs over water account for about $90 \%$ of the TCs in the global best-track data. Moreover, for TCs over land the calculated $U_{\text {TS-TC }}$ trend $\left(-0.89 \mathrm{~km} \mathrm{~h}^{-1}\right.$ decade $\left.^{-1}\right)$ is significant at the $95 \%$ confidence level (Fig. 4c), while $U_{\mathrm{TS}}$ exhibits a weak and insignificant increasing trend $\left[0.01 \mathrm{~km} \mathrm{~h}^{-1}\right.$ decade $^{-1}$; also see Extended Data Table 2 in Kossin (2018)]. These results imply that the relatively strong TCs dominate the global slowing trend, which compounds the 


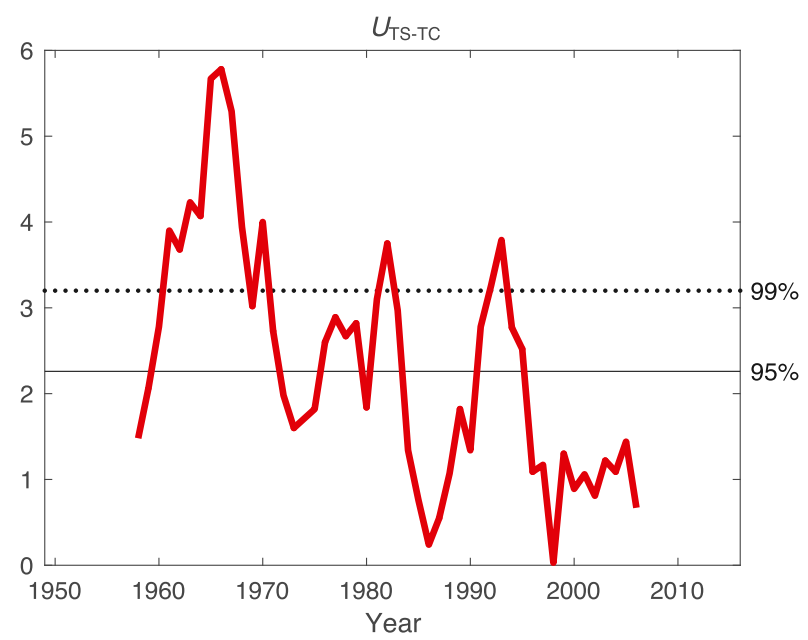

FIG. 5. Decadal abrupt change of $U_{\text {TS-TC. Moving } t \text { test of } 10}$ years for $U_{\text {TS-TC }}$ based on the global best-track dataset of IBTrACS. The dashed (dotted) horizontal line indicates the 95\% (99\%) confidence level.

effects of TC-induced rain and wave as stronger TCs are linked to greater rain rate over land and wave height over water (Lonfat et al. 2004; Sampson et al. 2010; Lazarus et al. 2013; Kossin 2018).

Trends of the $U_{\mathrm{TS}-\mathrm{TC}}$ time series over water and over land are different in the period of 1949-2016 (Figs. 4a-c): the trend in the previous period (e.g., 1949-82) is the cause of the slowing trend, but the trend in the recent period (e.g., 1982-2016) is essentially flat and even reversed. Consistent with the results in Kim et al. (2020), an abrupt decadal change occurred in 1982 based on the best track datasets, and is significant above the 99\% confidence level (Fig. 5). Note that there were also two significant abrupt decadal changes during the period of 1949-2016: one occurred in 1966 and the other in 1993 when the $U_{\text {TS-TC }}$ trend changed from flat (increasing) to decreasing (flat) (Figs. 4a and 5). Since the changepoint of 1982 separates the whole study period (1949-2016) into two periods with similar lengths (1949-82 and 1982-2016), we investigate different trends in the previous period (1949-82) and recent period (1982-2016) next.

\section{c. Possible causes for the decreasing trend of translation speed}

As the translation speed is controlled largely by the largescale environmental steering flow (Chan and Gray 1982), it is necessary to examine the contribution of steering flow change to the trend of TC translation speed. Here, for individual TC records, steering flow $\left(U_{\mathrm{SF}}\right)$ is defined as the averaged flow within a $5^{\circ}-7^{\circ}$ latitude band centered at the TC center location and between 850 and $300 \mathrm{hPa}$ (Holland 1993). As expected, there is a strong linear relation between the magnitude of $U_{\mathrm{TS}-\mathrm{TC}}$ and the magnitude of $U_{\mathrm{SF}}$, with a correlation coefficient of $0.61\left(p<10^{-7}\right)$ (Figs. 4a,d). For the TCs over water, the statistics are quite similar to those of the total TCs, since they account for about $90 \%$ of the total TC samples in the global best-track data (Figs. 4b,e). For the TCs over land, despite the relatively low correlation coefficient between $U_{\mathrm{TS}-\mathrm{TC}}$ and $U_{\mathrm{SF}}$ (0.46) (caused by small sample size and terrain effect), the correlation coefficient is still statistically significant above the 99.9\% confidence level (Figs. 4c,f). Moreover, both $U_{\text {TS-TC }}$ and $U_{\mathrm{SF}}$ exhibit similar decreasing trends (Figs. 4a-f). These results strongly suggest that the decreasing trend of $U_{\mathrm{SF}}$ is the key factor for the slowdown of global TCs. Furthermore, consistent with the difference in $U_{\text {TS-TC }}$ trend between the two periods of 1949-82 and 1982-2016 (Figs. 4a-c), the trend of $U_{\mathrm{SF}}$ in the previous period (1949-82) was much larger than that in the recent period (1982-2016) (Figs. 4d-f). When the steering flow is removed (regressed), the residual slowing rate is found to decrease substantially in the previous period (Figs. $4 \mathrm{~g}-\mathrm{i}$ ). This provides further evidence supporting the close relationship between TC translation speed and steering flow. In addition, $U_{\mathrm{SF}}$ is somewhat smaller than $U_{\mathrm{TS}-\mathrm{TC}}$ (Figs. 4a-f). This is consistent with the finding by Chan and Gray (1982), which showed that TCs in general move faster than the steering flow by about $1 \mathrm{~m} \mathrm{~s}^{-1}$.

Our results suggest that the large decreasing trend of upperlevel steering flow may be an important reason for the difference between $U_{\text {TS-TC }}$ and $U_{\text {TS }}$ trends (Fig. 6). As the vertical range of a TC is associated with $\mathrm{TC}$ intensity, stronger (weaker) TCs are steered more by upper-level (lower-level) winds [e.g., the wind above (below) $500 \mathrm{hPa}$ ]. Thereby, $U_{\mathrm{TS}-\mathrm{TC}}$ $\left(U_{\mathrm{TS}}\right)$, which is mainly determined by stronger (weaker) TCs accounting for the majority of all TC samples in terms of PDI (number) (Figs. 2a,d), is expected to be controlled more by the upper-level (lower-level) steering flow. Figure 6 clearly shows that the calculated trend of upper-level steering flow is much larger than the trend of lower-level steering flow. This further contributes to the large difference between $U_{\mathrm{TS}-\mathrm{TC}}$ and $U_{\mathrm{TS}}$ trends.

As suggested by Kossin (2019), it is the weakening of tropical atmospheric circulation that is expected to lead to a slowdown of TC steering flow and thus a slowdown of TC translation speed. However, this view has been questioned by some recent studies due to the data inhomogeneity related to changes in observational capability in the past decades (Guglielmi 2018; Kossin 2019; Lanzante 2019; Moon et al. 2019; Yamaguchi et al. 2020; Zhang et al. 2020). To estimate the impact of tropical circulation weakening induced by global warming, we investigate the changes of mean tropical wind speed, and of zonal and meridional wind components (Fig. 7). In this study, the tropical circulation (i.e., mean tropical wind speed) is defined as the mean winds between 850 and $300 \mathrm{hPa}$ in the TC main development region (the belts of $45^{\circ}-5^{\circ} \mathrm{S}$ and $5^{\circ}-$ $45^{\circ} \mathrm{N}$ ) during the TC season (July-October in the Northern Hemisphere and January-March in the Southern Hemisphere). Despite the large difference in their trends (Figs. 4a and 7a), the time series of $U_{\mathrm{TS}-\mathrm{TC}}$ and tropical circulation are significantly correlated with a correlation coefficient of $0.49(p<0.001)$ over the period of 1949-2016. Consistent with previous studies (Bellomo and Clement 2015; He and Soden 2015; He et al. 2017), the strength of the mean tropical atmospheric circulation was indeed weakened in the past decades. Moreover, the weakening occurred mainly in the zonal direction rather than in the meridional direction. This is also consistent with the findings of 

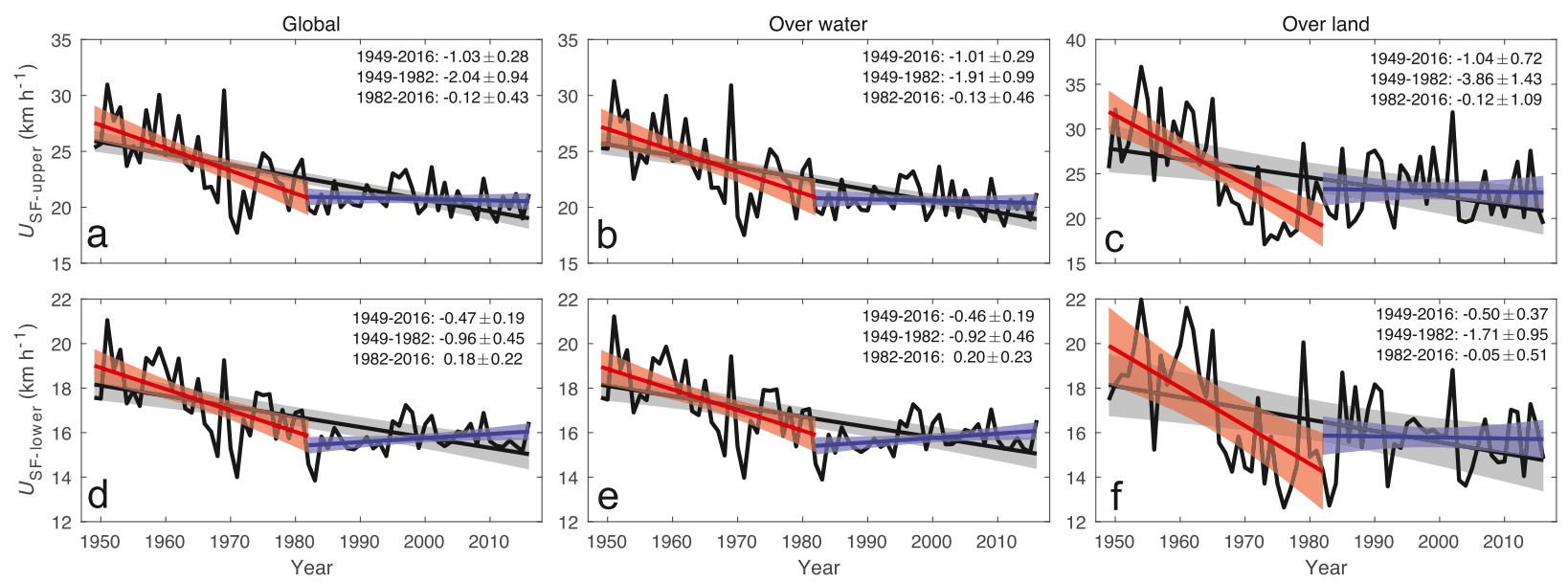

FIG. 6. Time series of annual-mean upper- and lower-level steering flows of TCs over the globe and the land, and their linear trends. The upper level is from 500 to $300 \mathrm{hPa}$, and the lower level is from 850 to $500 \mathrm{hPa}$. The period of the time series is 1949-2016. Linear trends (solid lines) are shown with their $95 \%$ two-sided confidence bounds (shading), which are also quantitatively presented (annotated values; $\mathrm{km} \mathrm{h}^{-1}$ decade $^{-1}$ ). Different colors of lines and shadings represent the trends and bounds during different periods (black: 1949-2016; red: 1949-82; blue: 1982-2016).

previous studies, which indicated that the zonally asymmetric part of the tropical circulation (e.g., the Walker circulation) weakened more than the zonally symmetric part (e.g., the Hadley cell) (Vecchi and Soden 2007; Lu et al. 2007; Bellomo and Clement 2015). More importantly, the decreasing trends of both zonal and meridional components of tropical circulation are all much smaller than those of the steering flow. This implies that the weakening of tropical circulation does not seem to be the only reason for the global slowdown of TC steering flow, and thus its translation speed, in the past decades (1949-2016).

In fact, changes in annual-mean TC steering flow can be deemed to be the joint effect of the change in large-scale circulation over TC main development region (e.g., tropical circulation) and the change in TC tracks (e.g., interbasin trend and latitudinal shift). In this study, due to the smaller slowing trend of tropical circulation compared with that of TC steering flow (Figs. 4d and 7a), the change of TC tracks is expected to be an important reason for the global slowdown of TC steering flow and thus TC translation speed.
To estimate the contributions of these two factors, namely, TC-track change and large-scale circulation change, we carry out a simple test using variable-controlling approach. The first (last) 15-yr period of 1949-63 (2002-16) is taken as the period when TC translation speed is relatively high (low), referred to as period A (period B). For each period, the 15-yr-averaged monthly winds are calculated for each month from January to December. Together with the information of TC tracks, the 15-yr-averaged steering flows of the two periods are also recalculated. Specifically, for every TC in period A (B), its 15 -yr-averaged steering flow is calculated with its surrounding winds in the month of the TC (i.e., one month from January to December) averaged in period A (B). The average of the 15-yr-averaged steering flows of all the TCs in period A (B) can be considered as the 15 -yr-averaged steering flow in period $\mathrm{A}$ (B). It is necessary to validate the reasonableness of $15-\mathrm{yr}-$ averaged steering flows when estimating the contributions of the two factors. Results show that although the recalculated steering flow is somewhat smaller than the original steering
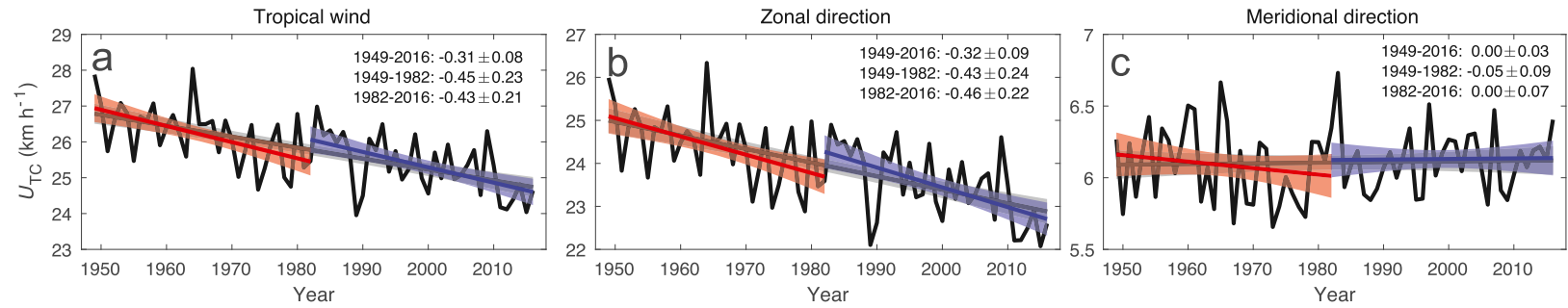

FIG. 7. Time series of annual-mean tropical circulation and its zonal and meridional components, and their linear trends. The period of the time series is 1949-2016. Linear trends (solid lines) are shown with their 95\% two-sided confidence bounds (shading), which are also quantitatively presented (annotated values; $\mathrm{km} \mathrm{h}^{-1} \mathrm{decade}^{-1}$ ). Different colors of lines and shadings represent the trends and bounds during different periods (black: 1949-2016; red: 1949-82; blue: 1982-2016). The confidence bounds of the trends have been adjusted for autocorrelation as needed. Tropical circulation is defined as the mean winds between 850 and $300 \mathrm{hPa}$ in the TC main development region (the belts of $45^{\circ}-5^{\circ} \mathrm{S}$ and $5^{\circ}-45^{\circ} \mathrm{N}$ ) during the TC season (July-October in the Northern Hemisphere and January-March in the Southern Hemisphere). 
TABLE 1. Calculated time-averaged original TC steering flow $\left(U_{\mathrm{SF}}\right)$ and recalculated time-averaged TC steering flow using 15 -yraveraged wind $\left(U_{\mathrm{SF}-15 \mathrm{Y}}\right)$, and their zonal and meridional components in period A (1949-63) and period B (2002-16). Units: $\mathrm{m} \mathrm{s}^{-1}$.

\begin{tabular}{lcc}
\hline & Period A & Period B \\
\hline$U_{\mathrm{SF}}$ & 22.0 & 17.8 \\
Zonal component of $U_{\mathrm{SF}}$ & 19.9 & 16.0 \\
Meridional component of $U_{\mathrm{SF}}$ & 6.2 & 5.2 \\
$U_{\mathrm{SF}-15 \mathrm{Y}}$ & 21.0 & 16.4 \\
Zonal component of $U_{\mathrm{SF}-15 \mathrm{Y}}$ & 19.7 & 15.4 \\
Meridional component of $U_{\mathrm{SF}-15 \mathrm{Y}}$ & 4.6 & 3.6 \\
\hline
\end{tabular}

flow (without the 15-yr average) due to the nonlinear effect, the difference in the recalculated steering flows between pe$\operatorname{riod} \mathrm{A}$ and period $\mathrm{B}$ is similar to that in the original steering flows between period A and period B (Table 1). Furthermore, similar results can be found in the meridional (zonal) component between the 15-yr-averaged and original steering flows (Table 1). Thereby, due to similar differences between period A and period $\mathrm{B}$, it is reasonable to use the variable-controlling approach with the 15-yr-averaged steering flow to estimate the contributions of TC-track change and large-scale circulation change between period $\mathrm{A}$ and period $\mathrm{B}$, and then to reveal possible causes for the slowdown of TC steering flow and thus TC translation speed.

Next, to compare the individual contributions of the two factors to the steering flow, monthly averaged winds for period $\mathrm{A}$ and period $\mathrm{B}$ are switched by using the variable-controlling approach. For example, the contribution of TC-track change can be estimated by comparing the 15 -yr-averaged steering flow using the TC tracks in period A (B) and the averaged winds in period $\mathrm{B}(\mathrm{A})$, with the 15 -yr-averaged steering flow using the TC tracks in period A (B) and the averaged winds in period A (B). We find that the change of TC tracks makes a much larger contribution to the slowdown of the steering flow, compared with the change of the large-scale circulation (Table 2). Moreover, for the meridional and zonal components of the steering flow, the TC track change also plays a much more important role than the large-scale circulation change. This indicates that compared with the weakening of tropical circulation, the change of TC tracks contributes much greater to the slowdown of TC steering flow and thus TC translation speed. This partly explains why there exists a discrepancy between the relatively small decrease of tropical circulation and the relatively large decrease of TC steering flow over the globe (Figs. 4d and 7a). However, this does not necessarily mean that a true climate signal (e.g., weakening of tropical circulation under global warming, which is relatively less sensitive to data inhomogeneity) plays an unimportant role in determining the global slowdown of TC translation speed. Kossin (2018, 2019) pointed out that formal attribution studies, which utilize carefully controlled numerical simulations, are required to figure out the explicit relationship between the trend of TC translation speed and anthropogenic forcing when all other factors are removed.
TABLE 2. Sensitivity of TC steering flow to changes of TC track and large-scale circulation. The calculated time-averaged TC steering flow, along with its zonal and meridional components, with different averaged TC track and large-scale circulation during period A (1949-63) and period B (2002-16) are listed. Units: $\mathrm{m} \mathrm{s}^{-1}$.

\begin{tabular}{cccc}
\hline \hline & & $\begin{array}{c}\text { Circulation } \\
\text { in period A }\end{array}$ & $\begin{array}{c}\text { Circulation } \\
\text { in period B }\end{array}$ \\
\hline TC steering & Track in period A & 21.0 & 20.3 \\
flow & Track in period B & 17.6 & 16.4 \\
Zonal & Track in period A & 19.7 & 19.3 \\
component & Track in period B & 16.5 & 15.4 \\
Meridional & Track in period A & 4.6 & 4.2 \\
component & Track in period B & 3.8 & 3.6 \\
\hline
\end{tabular}

Change of TC tracks mainly affects the trend of global TC translation speed in two ways: interbasin trend, and latitudinal shift (Kossin 2019; Lanzante 2019; Moon et al. 2019; Yamaguchi et al. 2020; Zhang et al. 2020). Before reaching a robust conclusion on the causes for the global slowdown of TC translation speed, it is necessary to investigate whether or not the interbasin trend and latitudinal shift contribute greatly to the global slowdown of TC translation speed, and whether or not they are caused by artifacts or true climate signal.

\section{d. Interbasin trend}

Despite $U_{\text {TS-TC }}$ being comparatively insensitive to advancement of TC detection technique (i.e., data inhomogeneity) in a basin (Fig. 1), this does not mean that the annual-mean $U_{\text {TS-TC }}$ globally is not sensitive to the inhomogeneous improvement of TC detection technique in different basins, such as the introduction of satellite remote sensing. The global slowing trend is partly attributed to the introduction of geostationary satellites as the satellite coverage started to include the eastern Pacific in 1966 (Landsea 2007) and the Southern Hemisphere in 1981 (Schreck et al. 2014; Kossin 2018; Lanzante 2019), following the increases of the percentage of TCs in the eastern Pacific and Southern Hemisphere, which are characterized by relatively slower translation speeds compared with those in the North Atlantic and western North Pacific (Figs. 8a,b). Moreover, unexpectedly, the slowing trend of global $U_{\text {TS-TC }}$ is larger than any trend in an individual basin (Table 3 data). This is due to interbasin trend, namely, the decrease (increase) of the percentage of TC number over a basin with relatively higher (lower) $U_{\text {TS-TC }}$, such as the North Atlantic and western North Pacific (eastern Pacific, northern Indian Ocean, and Southern Hemisphere) in the past decades (Fig. 8b). Therefore, the interbasin trend is likely to be caused by the data artifacts related to the coverage of geostationary satellites, and contributes greatly to the global slowdown of $U_{\mathrm{TS}-\mathrm{TC}}$.

\section{e. Latitudinal shift}

Similar to the effect of interbasin trend, the latitudinal shift related to the inhomogeneous improvement of TC detection technique at different latitudes also contributes to the global slowdown of TC translation speed. Due to the data inhomogeneity related to changes in observational capability, there was an abrupt increase of the percentage of low $U_{\text {TS-TC }}$ TCs 

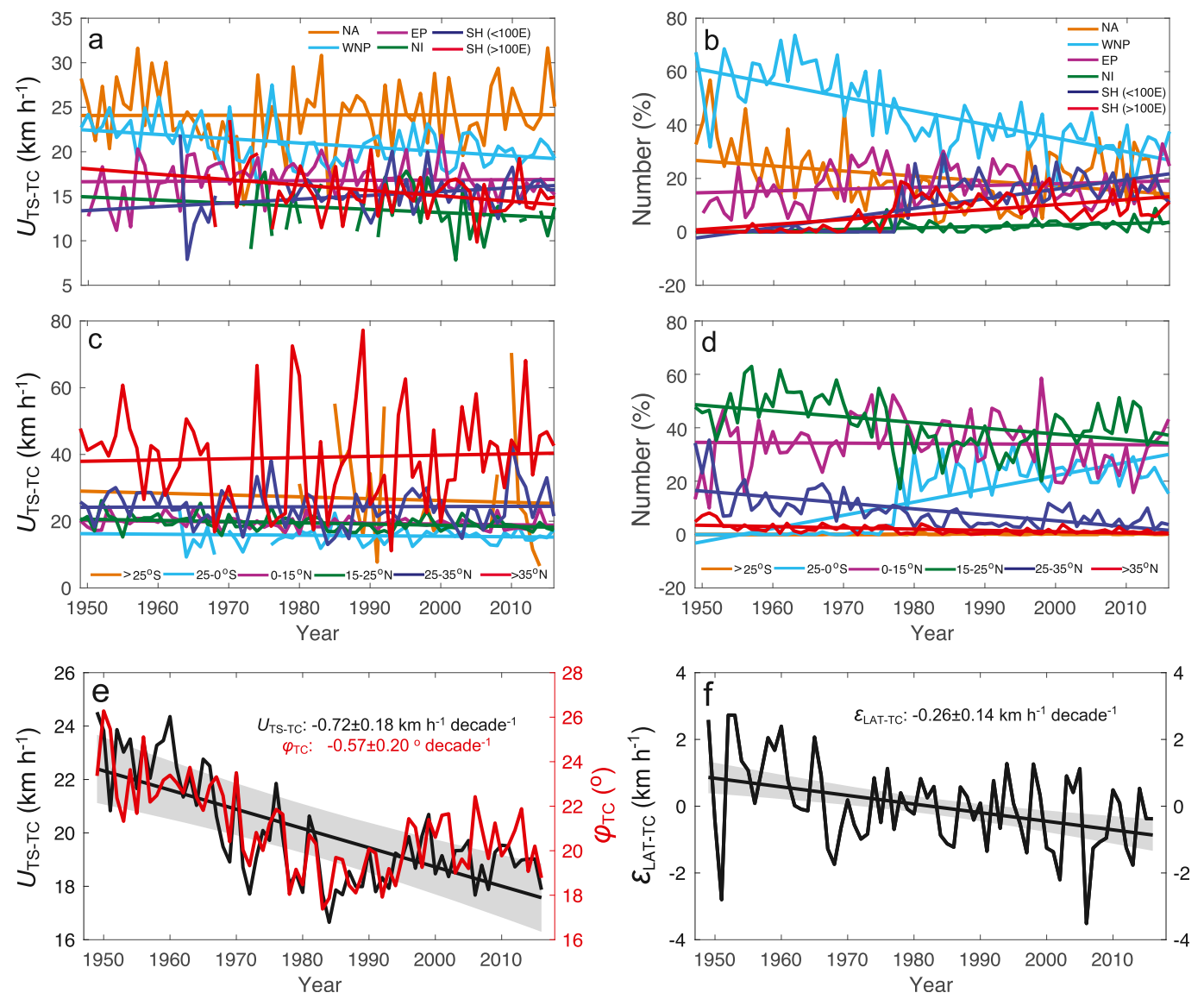

FIG. 8. Contributions of interbasin trend and latitudinal shift to global TC translation speed. (a),(b) Time series of annual-mean TC translation speed excluding TDs, percentages of TC number, and their linear trends in various ocean basins, including the North Atlantic, western North Pacific, eastern North Pacific, northern Indian Ocean, and the regions west and east of $100^{\circ} \mathrm{E}$ in the Southern Hemisphere and (c),(d) in latitude belts (i.e., $>25^{\circ} \mathrm{S}, 25^{\circ}-0^{\circ} \mathrm{S}$, $0^{\circ}-15^{\circ} \mathrm{N}, 15^{\circ}-25^{\circ} \mathrm{N}, 25^{\circ}-35^{\circ} \mathrm{N},>35^{\circ} \mathrm{N}$ ). (e) Time series of annual-mean TC translation speed (black) and latitude (red) excluding TDs (i.e., $U_{\mathrm{TS}-\mathrm{TC}}$ and $\varphi_{\mathrm{TC}}$ ). (f) Time series of the residual of $U_{\mathrm{TS}-\mathrm{TC}}$ with $\varphi_{\mathrm{TC}}$ variability removed $\left(\varepsilon_{\mathrm{LAT}-\mathrm{TC}}\right)$. Linear trends (solid lines) are shown in all the panels. The $95 \%$ two-sided confidence intervals of the linear trend (black shading) are shown, which are also quantitatively presented (annotated values) in the two bottom panels. Lines in (a) and (c) are discontinuous, due to the lack of records.

between $25^{\circ} \mathrm{S}$ and the equator in the late 1970 s (Figs. $8 \mathrm{c}, \mathrm{d}$ ). This contributes to the global slowdown of $U_{\mathrm{TS}-\mathrm{TC}}$.

Similar to the definition of $U_{\text {TS-TC }}$, we also use the measure of the annual-mean TC-center latitude with only the TC records reaching the intensity threshold of $17 \mathrm{~m} \mathrm{~s}^{-1}\left(\varphi_{\mathrm{TC}}\right)$ to investigate the relationship between latitudinal shift and global slowdown of TC translation speed. As expected, there is a strong positive relationship between $U_{\mathrm{TS}-\mathrm{TC}}$ and $\varphi_{\mathrm{TC}}$, with a correlation coefficient of 0.78 , which indicates that latitudinal shift has a strong impact on the change of TC translation speed (Fig. 8e). This is somewhat against the assumption of Kossin (2018); that is, the poleward migration of TCs tends to reduce TC's "beta drift" (Smith 1993) and thus TC translation speed. To further investigate the contribution of latitudinal shift, we calculate the residuals of annual-mean $U_{\mathrm{TS}-\mathrm{TC}}$ regressed onto $\varphi_{\mathrm{TC}}$. Following the method of Kossin et al. (2014), the annualmean $\varphi_{\mathrm{TC}}$ variability was removed from the annual-mean
$U_{\mathrm{TS}-\mathrm{TC}}$ time series by regressing $U_{\mathrm{TS}-\mathrm{TC}}$ onto $\varphi_{\mathrm{TC}}$, and the residuals were analyzed. When $\varphi_{\mathrm{TC}}$ is removed from $U_{\mathrm{TS}-\mathrm{TC}}$, the residual TC translation speed rate $\left(\varepsilon_{\mathrm{LAT}-\mathrm{TC}}\right)$ is found to decrease by nearly $60 \%$ (Fig. 8f). Moreover, as expected, the regression coefficients are statistically significant, and $\varphi_{\text {TC }}$ explains $60.1 \%$ of the $U_{\text {TS-TC }}$ variance, which provides further evidence on the important role of latitudinal shift. Overall, the latitudinal shift tends to be partly caused by data inhomogeneity, and contributes greatly to the global slowdown of TC translation speed.

\section{Summary and discussion}

In this study, we investigate the relationship between TC translation speed trend and TC intensity, and reveal possible causes for the TC translation speed trend. Our results show that the global slowing trend without weak TC moments $\left(\leq 17 \mathrm{~m} \mathrm{~s}^{-1}\right.$ ) (i.e., $U_{\mathrm{TS}-\mathrm{TC}}$ trend, $-0.72 \pm 0.31 \mathrm{~km} \mathrm{~h}^{-1}$ decade $^{-1}$ ) 
TABLE 3. Trends in TC translation speed excluding TDs (i.e., $U_{\mathrm{TS}-\mathrm{TC}}$ ) and their statistics. The changes are shown as trends and percentage changes over the period 1949-2016 in various regions. Significance is shown by the $p$ value of the regression and confidence interval of the trend. When identified by an asterisk, the confidence interval is based on the effective degrees of freedom adjusted for serial correlation [see methods section in Kossin (2018)]. Significant trends, determined on the basis of confidence intervals after serial correlation as needed, are shown in bold.

\begin{tabular}{|c|c|c|c|c|}
\hline Basin & Period & $\begin{array}{l}\text { Trend and its } 95 \% \text { confidence } \\
\text { interval }\left(\mathrm{km} \mathrm{h}^{-1} \text { decade }^{-1}\right)\end{array}$ & $\begin{array}{c}\text { Change } \\
(\%)\end{array}$ & $\begin{array}{c}p \text { value } \\
\text { (uncorrected) }\end{array}$ \\
\hline \multirow[t]{3}{*}{ Globe } & 1949-2016 & $-0.72 \pm 0.31$ & -21.53 & $<10^{-10_{*}}$ \\
\hline & $1949-82$ & $-1.58 \pm 0.44$ & -21.83 & $<10^{-7}$ \\
\hline & 1982-2016 & $0.26 \pm 0.27$ & 4.82 & 0.07 \\
\hline \multirow[t]{3}{*}{ North Atlantic } & 1949-2016 & $0.01 \pm 0.46$ & -0.39 & 0.95 \\
\hline & $1949-82$ & $-1.15 \pm 1.29$ & -14.67 & 0.10 \\
\hline & 1982-2016 & $0.51 \pm 1.17$ & 7.41 & 0.40 \\
\hline \multirow[t]{3}{*}{ Western North Pacific } & 1949-2016 & $-0.59 \pm 0.18$ & -17.93 & $<10^{-7}$ \\
\hline & $1949-82$ & $-1.12 \pm 0.55$ & -16.09 & $<10^{-3}$ \\
\hline & 1982-2016 & $0.06 \pm 0.32$ & 1.17 & 0.70 \\
\hline \multirow[t]{3}{*}{ Eastern Pacific } & 1949-2016 & $-0.09 \pm 0.26$ & -3.47 & 0.51 \\
\hline & $1949-82$ & $0.98 \pm 0.86$ & 20.55 & 0.04 \\
\hline & $1982-2016$ & $-0.58 \pm 0.46$ & -11.49 & 0.02 \\
\hline \multirow[t]{3}{*}{ Northern Indian Ocean } & $1949-2016$ & $0.11 \pm 0.23$ & 5.99 & 0.35 \\
\hline & $1949-82$ & $0.36 \pm 0.56$ & 9.98 & 0.22 \\
\hline & $1982-2016$ & $-0.85 \pm 0.62$ & -19.64 & 0.01 \\
\hline \multirow[t]{3}{*}{ Southern Hemisphere $\left(<100^{\circ} \mathrm{E}\right)$} & 1949-2016 & $-0.02 \pm 0.22$ & -0.86 & 0.86 \\
\hline & $1949-82$ & $1.08 \pm 0.64$ & 25.13 & $<10^{-2}$ \\
\hline & $1982-2016$ & $0.49 \pm 0.37$ & 11.90 & 0.01 \\
\hline \multirow[t]{3}{*}{ Southern Hemisphere $\left(>100^{\circ} \mathrm{E}\right)$} & 1949-2016 & $-0.40 \pm 0.20$ & -15.98 & $<10^{-3}$ \\
\hline & $1949-82$ & $-0.01 \pm 0.54$ & -0.24 & 0.97 \\
\hline & $1982-2016$ & $-0.05 \pm 0.53$ & -1.11 & 0.86 \\
\hline
\end{tabular}

is about double of that with weak TC moments in Kossin (2018) $\left(-0.30 \pm 0.11 \mathrm{~km} \mathrm{~h}^{-1}\right.$ decade $\left.^{-1}\right)$. This is because the trend of TC translation speed slowdown is dominated by stronger TCs, which compounds the effects of TC slowdown on locally accumulated TC damage (e.g., local rainfall totals over land and local wave power over water).

We also show that the decreasing trend of large-scale steering flow is the key factor for the slowdown of global TCs, which effectively explains the large difference between the $U_{\text {TS-TC }}$ trend in the previous period (1949-82) and the trend in the recent period (1982-2016). Moreover, the calculated trend of upper-level steering flow is much larger than that of lower-level steering flow. This may be an important cause for the large difference between the trend of $U_{\text {TS-TC }}$ and the trend in Kossin (2018) as stronger (weaker) TCs tend to be controlled more by upper-level (lower-level) steering flow.

Our results further indicate that the changes of TC tracks (including interbasin trend and latitudinal shift) make a much larger contribution to the slowing trend compared with the weakening of tropical circulation, which is related to anthropogenic warming. Note that the effects of interbasin trend and latitudinal shift are not independent of each other; they are largely coincident with each other, and hard to separate. More importantly, both interbasin trend and latitudinal shift, which are partly attributed to data inhomogeneity, contribute greatly

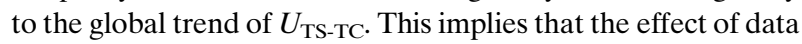
inhomogeneity can strongly affect the global trend of $U_{\text {TS-TC, }}$ since the change of TC tracks is partly attributed to data inhomogeneity. Note that this does not necessarily mean that a true climate signal (e.g., weakening of tropical circulation under global warming) makes an unimportant contribution to the global slowdown of TC translation speed. Careful attribution studies, which utilize carefully controlled numerical simulations, are required to identify true relationship between the trend of TC translation speed and anthropogenic forcing when all other factors are removed.

Acknowledgments. We thank Drs. J. P. Kossin, M. Yamaguchi, and R. K. Smith for their constructive comments that helped improve the paper. This work was funded by the National Natural Science Foundation of China (Grants 42075035, 41675077, and 41605072). Y. Sun and Z. Z. designed the research. Y. Sun, Z. Z., T. L., and Y. L. performed the analyses with input from Y. Sun and Y. Shen. Y. Sun and Z. Z. wrote the article with input from all authors. The authors declare that they have no competing interests. All the data used in the analyses are available from the corresponding author upon request.

\section{REFERENCES}

Bellomo, K., and A. C. Clement, 2015: Evidence for weakening of the Walker circulation from cloud observations. Geophys. Res. Lett., 42, 7758-7766, https://doi.org/10.1002/2015GL065463.

Bowyer, P. J., and A. W. MacAfee, 2005: The theory of trapped-fetch waves with tropical cyclones-An operational perspective. Wea. Forecasting, 20, 229-244, https://doi.org/10.1175/WAF849.1.

Chan, J. C. L., and W. M. Gray, 1982: Tropical cyclone movement and surrounding flow relationships. Mon. Wea. Rev., 110, 1354-1374, https:// doi.org/10.1175/1520-0493(1982)110<1354:TCMASF>2.0.CO;2. 
Chan, K. T. F., 2019: Are global tropical cyclones moving slower in a warming climate? Environ. Res. Lett., 14, 104015, https:// doi.org/10.1088/1748-9326/ab4031.

Chien, F. C., and H. C. Kuo, 2011: On the extreme rainfall of Typhoon Morakot (2009). J. Geophys. Res., 116, D05104, https://doi.org/10.1029/2010JD015092.

Emanuel, K. A., 2005: Increasing destructiveness of tropical cyclones over the past 30 years. Nature, 436, 686-688, https:// doi.org/10.1038/nature03906.

— 2017: Assessing the present and future probability of Hurricane Harvey's rainfall. Proc. Natl. Acad. Sci. USA, 114, 12 681-12 684, https://doi.org/10.1073/pnas.1716222114.

George, J. E., and W. M. Gray, 1976: Tropical cyclone motion and surrounding parameter relationships. J. Appl. Meteor., 15, 1252-1264, https://doi.org/10.1175/1520-0450(1976)015<1252: TCMASP $>2.0 . \mathrm{CO} ; 2$.

Guglielmi, G., 2018: Hurricanes around the world linger longer. Nature, 558, 15-16, https://doi.org/10.1038/d41586-018-05324-5.

Gutmann, E. D., and Coauthors, 2018: Changes in hurricanes from a 13-yr convection-permitting pseudo-global warming simulation. J. Climate, 31, 3643-3657, https://doi.org/10.1175/ JCLI-D-17-0391.1.

He, C., B. Wu, L. Zou, and T. Zhou, 2017: Responses of the summertime subtropical anticyclones to global warming. J. Climate, 30, 6465-6479, https://doi.org/10.1175/JCLI-D-16-0529.1.

He, J., and B. J. Soden, 2015: Anthropogenic weakening of the tropical circulation: The relative roles of direct $\mathrm{CO}_{2}$ forcing and sea surface temperature change. J. Climate, 28, 8728-8742, https://doi.org/10.1175/JCLI-D-15-0205.1.

Held, I. M., and B. J. Soden, 2006: Robust responses of the hydrological cycle to global warming. J. Climate, 19, 5686-5699, https://doi.org/10.1175/JCLI3990.1.

Holland, G. J., 1993: Tropical Cyclone Motion. Bureau of Meteorology Research Centre, 337 pp.

Kalnay, E., and Coauthors, 1996: The NCEP/NCAR 40-Year Reanalysis Project. Bull. Amer. Meteor. Soc., 77, 437-472, https:// doi.org/10.1175/1520-0477(1996)077<0437:TNYRP>2.0.CO;2.

Kim, S.-H., I.-J. Moon, and P.-S. Chu, 2020: An increase in global trends of tropical cyclone translation speed since 1982 and its physical causes. Environ. Res. Lett., 15, 094084, https://doi.org/ 10.1088/1748-9326/ab9e1f.

Knapp, K. R., M. C. Kruk, D. H. Levinson, H. J. Diamond, and C. J. Neumann, 2010: An overview of the International Best Track Archive for Climate Stewardship. Bull. Amer. Meteor. Soc., 91, 363-376, https://doi.org/10.1175/2009BAMS2755.1.

Knutson, T. R., and Coauthors, 2010: Tropical cyclones and climate change. Nat. Geosci., 3, 157-163, https://doi.org/10.1038/ngeo779.

Kossin, J. P., 2018: A global slowdown of tropical-cyclone translation speed. Nature, 558, 104-107, https://doi.org/10.1038/ s41586-018-0158-3.

_ 2019: Reply to: Moon, I.-J. et al.; Lanzante, J. R. Nature, 570, E16-E22, https://doi.org/10.1038/s41586-019-1224-1.

_ , K. A. Emanuel, G. A. Vecchi, 2014: The poleward migration of the location of tropical cyclone maximum intensity. Nature, 509, 349-352, https://doi.org/10.1038/nature13278.

Landsea, C. W., 2007: Counting Atlantic tropical cyclones back to 1900. Eos, Trans. Amer. Geophys. Union, 88, 197-202, https:// doi.org/10.1029/2007EO180001.

Lanzante, J. R., 2019: Uncertainties in tropical-cyclone translation speed. Nature, 570, E6-E15, https://doi.org/10.1038/s41586019-1223-2.
Lazarus, S. M., S. T. Wilson, M. E. Splitt, and G. A. Zarillo, 2013: Evaluation of a wind-wave system for ensemble tropical cyclone wave forecasting. Part I: Winds. Wea. Forecasting, 28, 297-315, https://doi.org/10.1175/WAF-D-12-00054.1.

Lin, Y., M. Zhao, and M. Zhang, 2015: Tropical cyclone rainfall area controlled by relative sea surface temperature. Nat. Commun., 6, 6591, https://doi.org/10.1038/ncomms7591.

Lonfat, M., F. D. Marks, and S. Chen, 2004: Precipitation distribution in tropical cyclones using the Tropical Rainfall Measuring Mission (TRMM) Microwave Imager: A global perspective. Mon. Wea. Rev., 132, 1645-1660, https://doi.org/ 10.1175/1520-0493(2004)132<1645:PDITCU>2.0.CO;2.

Lu, J., G. A. Vecchi, and T. Reichler, 2007: Expansion of the Hadley cell under global warming. Geophys. Res. Lett., 34, L06805, https://doi.org/10.1029/2006GL028443.

Moon, I.-J., S.-H. Kim, and J. C. L. Chan, 2019: Climate change and tropical cyclone trend. Nature, 570, E3-E5, https://doi.org/ 10.1038/s41586-019-1222-3.

Patricola, C. M., 2018: Tropical cyclones are becoming sluggish. Nature, 558, 36-37, https://doi.org/10.1038/d41586-018-05303-w.

Risser, M. D., and M. F. Wehner, 2017: Attributable human-induced changes in the likelihood and magnitude of the observed extreme precipitation during Hurricane Harvey. Geophys. Res. Lett., 44, 12 457-12 464, https://doi.org/10.1002/2017GL075888.

Sampson, C. R., P. A. Wittmann, and H. L. Tolman, 2010: Consistent tropical cyclone wind and wave forecasts for the U.S. Navy. Wea. Forecasting, 25, 1293-1306, https://doi.org/ 10.1175/2010WAF2222376.1.

Schreck, C. J., K. R. Knapp, and J. P. Kossin, 2014: The impact of best track discrepancies on global tropical cyclone climatologies using IBTrACS. Mon. Wea. Rev., 142, 3881-3899, https:// doi.org/10.1175/MWR-D-14-00021.1.

Smith, R. B., 1993: A hurricane beta-drift law. J. Atmos. Sci., 50, 3213-3215, https://doi.org/10.1175/1520-0469(1993)050<3213: AHBDL $>2.0 . \mathrm{CO} ; 2$.

Sun, Y., and Coauthors, 2017: Impact of ocean warming on tropical cyclone size and its destructiveness. Sci. Rep., 7, 8154, https:// doi.org/10.1038/s41598-017-08533-6.

_ , and Coauthors, 2018: A recent reversal in the poleward shift of western North Pacific tropical cyclones. Geophys. Res. Lett., 45, 9944-9952, https://doi.org/10.1029/2018GL079686.

Van Oldenborgh, G. J., and Coauthors, 2017: Attribution of extreme rainfall from Hurricane Harvey, August 2017. Environ. Res. Lett., 12, 124009, https://doi.org/10.1088/1748-9326/aa9ef2.

Vecchi, G. A., and B. J. Soden, 2007: Global warming and the weakening of the tropical circulation. J. Climate, 20, 43164340, https://doi.org/10.1175/JCLI4258.1.

,-- A. T. Wittenberg, I. Held, A. Leetmaa, and M. J. Harrison, 2006: Weakening of tropical Pacific atmospheric circulation due to anthropogenic forcing. Nature, 441, 73-76, https://doi.org/10.1038/nature04744.

Wang, C., L. Wu, J. Lu, Q. Liu, H. Zhao, W. Tian, and J. Cao, 2020: Interannual variability of the basinwide translation speed of tropical cyclones in the western North Pacific. J. Climate, 33, 8641-8650, https://doi.org/10.1175/JCLI-D-19-0995.1.

Yamaguchi, M., J. C. L. Chan, I.-J. Moon, K. Yoshida, and R. Mizuta, 2020: Global warming changes tropical cyclone translation speed. Nat. Commun., 11, 47, https://doi.org/ 10.1038/s41467-019-13902-y.

Zhang, G., H. Murakami, T. R. Knutson, R. Mizuta, and K. Yoshida, 2020: Tropical cyclone motion in a changing climate. Sci. Adv., 6, eaaz7610, https://doi.org/10.1126/sciadv.aaz7610. 